\title{
An Examination into the Defining Characteristics of Flexible Solar Aircraft Configurations through Optimization
}

\author{
Taylor McDonnell* and Andrew Ning \\ Brigham Young University, Provo, UT, 84602, USA
}

DOI: $10.2514 / 6.2019-3456^{*}$

\begin{abstract}
This paper examines the defining characteristics of various solar aircraft configurations through gradient-based multidisciplinary design optimization. We first present a general gradient-based solar aircraft optimization framework which accounts for nonlinear aeroelastic effects resulting from structural flexibility. We then apply this framework to several discrete SR-HALE aircraft geometric, structural, and propulsion system configuration choices to determine the defining characteristics of each configuration choice.
\end{abstract}

\section{Introduction}

Solar aircraft must be designed to be as efficient as possible to be able to achieve perpetual flight. A critical choice in the design process for these aircraft is that of the aircraft configuration, since this choice in large part determines the aerodynamic, structural, and performance issues which must be addressed during the remainder of the design process. Despite its importance, there seems to be no consensus regarding what configuration solar aircraft should have among researchers and companies. Among the designs that researchers have investigated are braced wing [1], blended wing body [2], unswept flying wing [3, 4], swept flying wing [5], and conventional aircraft configurations with varying numbers of tails [6-8]. Among the designs which have been or are currently being pursued by various companies are unswept flying aircraft (AeroVironment's Helios and Hawk30), swept flying wing aircraft (Facebook's Aquila), configurations with varying numbers of tails (Airbus's Zephyr and Aurora's Odysseus), and reconfigurable configurations made up of multiple independent sections (Aurora's Vulture). It is highly unlikely that all of these configurations are equally well suited to the solar aircraft mission, therefore further investigation into the impact of solar aircraft configuration choices on the performance of solar aircraft is merited.

Prior investigations into the impact of solar aircraft configuration choices in the context of the entire solar aircraft design problem have been performed by Nickol et al. [3,4], Burton et al. [8], and Colas et al. [5,6]. Nickol et al. investigated unswept flying wing solar aircraft, trussed-wing unswept flying wing solar aircraft, joined-wing solar aircraft, and unswept flying wing solar aircraft with auxiliary sun-tracking solar panels. Each of these designs were optimized using a solar aircraft multidisciplinary design optimization (MDO) framework. While none of the designs could meet the desired mission criteria, the original HELIOS-like unswept flying wing aircraft design and the unswept flying wing aircraft design with auxiliary solar panels proved to be the most feasible configurations, with the auxiliary solar panel design being more feasible for communication relay missions than configurations without auxiliary solar panels. Ultimately, however, Nickol et al. concluded that additional feasibility provided by auxiliary solar panels was likely not worth the additional complexity of their implementation. As part of their study, Nickol et al. also investigated the effectiveness of vertical solar panels compared to horizontal solar panels. They found vertical solar panels suffer from a directionality issue, in which they only spend a fraction of the day (near dawn and dusk) at an optimal or near-optimal angle with the sun. Therefore, while vertical solar panels outperform horizontal solar panels at dawn and dusk, horizontal

Copyright $\odot 2019$ by Taylor McDonnell and Andrew Ning

*Ph.D. Candidate, Department of Mechanical Engineering; taylormcd@byu.edu. Student AIAA.

${ }^{\dagger}$ Assistant Professor, Department of Mechanical Engineering; aning @ byu.edu. Senior AIAA.

${ }^{\ddagger}$ Published in the proceedings of the AIAA Aviation 2019 Forum. Any citations of this work should use the following reference: McDonnell, T. G. and Ning, A., An Examination into the Defining Characteristics of Flexible Solar Aircraft Configurations through Optimization, AIAA Aviation 2019 Forum, American Institute of Aeronautics and Astronautics, Jun. 2019 solar panels outperform vertical solar panels over the course of the day.

Burton et al. investigated the impact of multiple motors/propellers and battery pod placement on solar aircraft design for a conventional aircraft configuration through geometric programming [8]. They performed a number of studies on a conventional solar aircraft configuration with a single tail. These included investigations into the optimal number of battery pods and propellers. They found that maximum solar aircraft take-off weight was relatively insensitive to the number of battery pods used and that it is more efficient to have a small number of larger propellers, since propeller efficiency decreases with propeller count.

Colas et al. optimized flying wing, single boom, and twin boom solar aircraft configurations in a gradient-free optimization framework $[5,6]$. All of the considered aircraft configurations exhibited similar take-off weights over a wide range of latitude-band mission requirements. No aircraft configuration therefore appears to outperform the other aircraft configurations by a significant margin. The characteristics of each optimized design, however, differed. The twin-boom configuration both had a faster design airspeed than the single-boom configuration and had a higher aspect ratio resulting in increased aerodynamic efficiency. Wing weight was also reduced in the twin-boom concept relative to the single boom concept, which offset the increased boom and tail weight. Colas et al. also found swept flying wing solar aircraft to be primarily stability constrained rather than material failure constrained due to the presence of body freedom flutter.

Among the studies considering the entire solar aircraft design problem, only those performed by Colas et al. constrained optimized solar aircraft designs against flutter. Other studies therefore, do not capture solar aircraft design trade-offs associated with the impact of aeroelastic instabilities. Gradient-free optimization, however, is computationally limited to a small number of design variables because its computational expenses scale poorly with the number of design variables. Therefore, the purpose of this study is to investigate the impact of various solar aircraft configuration choices in greater detail than can be performed using gradient-free optimization while accounting for the impact of structural flexibility and aeroelastic instabilities.

\section{Methods}

One of the primary challenges of the gradient-free optimization is that its computational expense scales poorly with the number of design variables compared to gradient-based optimization. On the other hand, geometric programming, while extremely fast, is very restrictive, since it requires that the optimization problem be expressed using only monomial and posynomial objective and constraint functions. This makes including the impact of complex aeroelastic phenomenon such as flutter very difficult. A compromise between the two approaches is therefore to use gradient-based optimization, as its computational expenses scale better with the number of design variables used and only requires that objective and constraint functions are continuous and differentiable. This work, therefore, uses gradient-based optimization to optimize the various aircraft configurations, and builds off the authors' previous work in the area $[9,10]$. Details of the optimization framework used 
paper [10].

\section{A. Optimization Framework}

\section{Aircraft Aerodynamic and Structural Performance}

To minimize development time, we use the existing aeroelastic analysis program ASWING in our optimization framework for aerodynamic and structural performance calculations. ASWING is designed as a configuration development system for flexible aircraft and is appropriate for use on aircraft with flexible wings and fuselages of high to moderate aspect ratio. Since solar aircraft feature high aspect ratios in order to increase aerodynamic efficiency by reducing induced drag, this tool is appropriate for the preliminary design of solar aircraft.

Analyses that may be performed using ASWING include nonlinear static response analyses and coupled flight and aerostructural stability analyses performed through linearizing the general nonlinear aeroelastic model about trimmed operating states. Both of these analyses are used in this optimization framework. To decrease computational expenses, and to prevent unnecessary file input/output we also developed a wrapper to be able to call ASWING directly ${ }^{\mathrm{a}}$. We also developed a translated version of ASWING in the Julia programming language and used it with algorithmic differentiation provided by the ForwardDiff [11] package in order to obtain numerically exact derivatives.

\section{Beam Structural and Aerodynamic Properties}

ASWING models lifting and non-lifting aircraft surfaces as interconnected nonlinear Bernoulli-Euler beams. Aerodynamic performance is estimated using extended lifting-line theory, reminiscent of a Weissinger approach (i.e., a vortex panel method with multiple spanwise panels and one chordwise panel). Each bound vortex segment midpoint is located at the airfoil sections quarter-chord point, with a corresponding control point located downstream in the same direction as the bound vortex segment. The location of the control point may be chosen such that the local incompressible 2-D section lift-curve slope is reproduced. Assuming a lift slope of $2 \pi$ places the control point a half-chord downstream of the bound vortex segment midpoint, as done by the standard vortex lattice method. Induced drag, lift, side force, and rolling moment coefficients are computed by ASWING in the $\mathrm{Tr}$ efftz Plane oriented perpendicular to the wind direction. Profile drag force is resolved into a friction drag contribution acting along the local net velocity and a pressure drag contribution acting perpendicular to the beam's spanwise axis and integrated along each beam. Further details of the implementation may be found in the ASWING theory guide [12].

In order to define each beam (lifting and non-lifting), ASWING requires that beam structural and aerodynamic properties are specified at each cross section. Therefore a method for obtaining beam structural properties given a specified section geometry, layup, and structural configuration as well as a method for obtaining local section two-dimensional aerodynamic properties is warranted. To obtain beam cross section stiffness and inertial properties, we use PreComp [13]. PreComp uses a modified classical laminate approach to determine composite beam stiffness and inertial properties. To determine beam cross section aerodynamic properties we use XFOIL [14]. The computational expense of running PreComp is small, therefore it is directly incorporated into the optimization framework. XFOIL is not incorporated directly into the optimization framework, but rather is used to generate a set of precomputed aerodynamic properties which are used in the optimization framework. This was done both due to the computational expense of running XFOIL in the optimization framework and because raw converged results obtained from XFOIL were occasionally discontinuous and thus unsuitable for use in gradient-based optimization.

The specific aerodynamic quantities of interest needed for defining cross-sectional aerodynamic properties in ASWING are the lift slope, zero lift angle of attack, friction drag coefficient, profile drag coefficient, and the quarter chord moment coefficient. Optionally, maximum and minimum lift coefficients may also be specified to limit

\footnotetext{
${ }^{a}$ This wrapper may be found at https: / / github. com/byuflowlab/ Aswing.jl
}

cross-sectional lift and impose drag penalties due to the local section stalling, however, we chose to constrain maximum and minimum lift coefficients separately in the optimization. In defining each of these quantities, we chose to use local section properties at each sections undeformed angle of attack, that is, the local lift slope, local friction drag coefficient, local profile drag coefficient, and the local quarter chord moment coefficient at each sections undeformed angle of attack. We also calculated the zero lift angle of attack based on the local lift coefficient and lift slope in order to yield the correct local angle of attack corresponding to the specified local lift coefficient as given by the following expression.

$$
\alpha_{L=0}=\alpha-\frac{c_{l}}{d c_{l} / d \alpha}
$$

For this study, to be able to capture airfoil thickness structural/aerodynamic trade offs, we precomputed aerodynamic properties for three families of airfoils created by modifying the thickness of three different airfoils in XFOIL. The airfoils we chose to use to construct our airfoil families were the low-Reynolds number E216 airfoil, the flying wing (reflexed) airfoil LA2573A (which was used on the AeroVironment Pathfinder), and the symmetric NACA 4 digit series airfoil sections. For each airfoil family, cross-sectional properties were computed at a variety of Reynolds numbers ranging from $5 \times 10^{4}$ to $1 \times 10^{6}$, thicknesses over chord ratios ranging from 0.1 to 0.2 , and angle of attacks ranging from $-20^{\circ}$ to $20^{\circ}$. Since XFOIL does not accurately predict and/or reliably converge on post-stall section aerodynamic coefficients, the Viterna method was used to extrapolate results to the post stall region. In practice, however, post-stall aerodynamic properties are not present in optimized designs since we constrain optimization results against local section stall, so the primary purpose of extrapolating the two-dimensional data is to allow the optimizer to take design steps outside the feasible design space while progressing towards a feasible, optimal design.

\section{Energy Capture, Storage, and Usage}

Energy capture and storage are constrained using two separate constraints. First, the aircraft must collect at least as much energy as it uses during any 24 hour period during the year. Second, the aircraft must carry at least enough battery mass to power night long flight at the design altitude. In both cases, winter solstice is the limiting 24 hour period during the year since that is when the least amount of solar energy is available and nights are longest. We assume each aircraft has solar panels which cover the upper side of each horizontal lifting surface and both sides of each vertical lifting surface. These solar panels have the same thickness as those used on the Solar Impulse $\left(135 \mu \mathrm{m}^{\mathrm{b}}\right)$ and have the density of silicon $\left(2328 \mathrm{~kg} / \mathrm{m}^{3}\right)$. We calculate solar flux by using the Simple Model of the Atmospheric Radiative Transfer of Sunshine (SMARTS) [15]. We assume battery specific energy is $350 \mathrm{Whr} / \mathrm{kg}$, however, we also limit battery depth of discharge to $80 \%$, effectively limiting battery specific energy to $280 \mathrm{Whr} / \mathrm{kg}$. Currently reported cell specific energies on Airbus's Zephyr have specific energies of $435 \mathrm{Whr} / \mathrm{kg}$ before accounting for packaging losses so the battery specific energy are a reasonable assumption for recently developed high-end lithium batteries.

While we constrain our optimized designs to have sufficient battery mass to power night long flight at a design altitude, in reality, less battery mass may be required for night long flight if potential energy storage is considered. We do not, however, consider potential energy storage in this study. Instead we assume that the aircraft performs large $3000 \mathrm{~m}$ orbits at the design altitude (with an initial north-facing orientation) so that steady state operating conditions at a constant design altitude may be assumed throughout this study. The roll necessary to maintain this orbit is determined by that of a coordinated turn:

$$
\phi=\tan ^{-1}\left(\frac{V^{2}}{g R}\right)
$$

where $V$ is cruise velocity, $g$ is gravity, and $R$ is the orbit radius. The aircraft's yaw angle is determined by assuming the aircraft is always oriented tangent to the orbit radius.

\footnotetext{
bhttps: //aroundtheworld. solarimpulse.com/adventure
} 
To determine the total amount of solar capture on the upper surface of the aircraft, we discretize each solar aircraft spanwise and chordwise into flat panels with associated roll, pitch, yaw, and area. This discretization is performed using the shape of the aircraft at the design operating point. Panel normal vectors are then compared with sun vectors throughout the day to determine the incident solar flux on each panel at each time step. This flux is numerically integrated across the 24 hour period and multiplied by panel area to determine the amount of solar energy captured by each panel. This energy capture is then reduced using a total solar panel system efficiency of $20 \%$. The Solar Impulse used $23 \%$ efficient solar panels, so the solar panel system efficiency we use in this paper is a conservative estimate. In part this conservative solar panel efficiency value was adopted to account for the reduction in actual effective solar panel area which may exist on actual solar aircraft prototypes and/or other solar panel system inefficiencies.

We calculate energy usage by integrating the total power required to operate each aircraft for 24 hours at steady level flight at design operating conditions. This is equivalent to a simple multiplication of the power required for steady-level flight by 24 hours. The power required for steady level flight is given by:

$$
P_{\text {req }}=\frac{V_{\infty} D}{\eta_{\text {motor }} \eta_{\text {prop }} \eta_{\text {other }}}+P_{\text {avionics }}+P_{\text {payload }}
$$

where $V_{\infty}$ is the freestream velocity, $D$ is the total aircraft drag, $\eta_{\text {motor }}$ is the motor efficiency, $\eta_{\text {prop }}$ is the propeller efficiency, $\eta_{\text {other }}$ is the efficiency of all other components of the propulsion system (assumed in this study to be 0.97$), P_{\text {avionics }}$ is the power required by the avionics system, and $P_{\text {payload }}$ is the power required by the payload.

We assume that fixed pitch propellers are used on all configurations with propeller non-dimensional properties being given in Fig. 1. We calculated these propeller performance curves using blade element momentum theory in a coupled SR-HALE trajectory and propulsion optimization study [16]. Propeller revolutions per minute is controlled by the optimizer indirectly by modifying the advance ratio. Propeller diameter is also modified by the optimizer.

We calculate motor efficiency in the optimization using a first order motor model. We follow the derivation provided by Drela, repeated here. We assume the torque is proportional to the current minus the no load current via the torque constant $K_{Q}$.

$$
Q_{m}=\left(I-I_{0}\right) / K_{Q}
$$

We also assume the back-EMF is proportional to the rotation rate $\Omega$ via the motor speed constant $K_{V}$.

$$
V_{m}=\Omega / K_{V}
$$

The motor voltage is then given by

$$
V=V_{m}+I R=\Omega / K_{v}+I R
$$

which can be manipulated to get the current.

$$
I=\left(V-\frac{\Omega}{K_{v}}\right) \frac{1}{R}
$$

The motor torque, shaft power and efficiency are then given by the following expressions:

$$
\begin{gathered}
Q_{m}=\left(I-I_{0}\right) / K_{Q} \\
P_{\text {shaft }}=Q_{m} \Omega \\
\eta_{m}=\frac{P_{\text {shaft }}}{I V}
\end{gathered}
$$

With zero losses $\left(I_{0}=0\right.$ and $\left.R=0\right)$ this model predicts motor efficiency to be given by

$$
\eta_{m}=\frac{K_{v}}{K_{Q}}
$$

therefore, due to energy conservation principles, we assume the two constants are equal. A motor may therefore be characterized by its internal resistance $(R)$, no load current $\left(I_{0}\right)$, and motor speed constant $\left(K_{V}\right)$.
To use this model in our optimization, we use the following empirical relationship between no load current and internal resistance, constructed using AstroFlight motor data [17]:

$$
R=0.0467 I_{0}^{-1.892}
$$

We then pass $I_{0}$ and $K_{V}$ to the optimizer to characterize the motor. $I_{0}$ and $K_{V}$ are constrained to be greater than $32 \mathrm{rpm} / \mathrm{V}$ and $0.1 \mathrm{~A}$, respectively to restrict the optimal motor to the range described by the empirical fit. The motor's efficiency is obtained by matching the propellers rotation rate and torque and rearranging the above expressions as follows.

$$
\begin{gathered}
I=Q_{m} K_{V}+I_{0} \\
V=\frac{\Omega}{K_{V}}+I R \\
\eta_{m}=\frac{Q_{m} \Omega}{I V}
\end{gathered}
$$

\section{Aerodynamic Constraints}

We use critical section theory to constrain aircraft stall during design operation. Lift coefficients are therefore constrained to be less than their respective sections maximum lift coefficient. We reduce maximum lift coefficients by $90 \%$ on the inboard portion of the wing and up to $80 \%$ on the outboard portions of the wing in order to provide a margin against stall and prevent tip stall by multiplying maximum lift coefficients by the following factor:

$$
G(y / b)= \begin{cases}0.9 & 0 \leq|y / b| \leq 0.25 \\ 0.9-1.6(|y / b|-0.25)^{2} & 0.25<|y / b| \leq 0.5\end{cases}
$$

We also constrain the Reynolds number for all lifting surfaces to be greater than $5 \times 10^{4}$, which is the minimum Reynolds number used when precomputing two-dimensional aerodynamic properties.

\section{Structural Constraints}

Imposed structural constraints are based on the flight envelope shown in Fig. 2. We set the maximum cruise equivalent airspeed (EAS) $5 \mathrm{~m} / \mathrm{s}$ above the design airspeed. The dive speed is set to $125 \%$ of the design cruise speed. Flutter is constrained up to $110 \%$ of the aircraft dive speed at the numbered operating points. Material failure and local buckling are constrained at both the lettered and numbered operating points and a safety factor of 1.5 is applied to both modes of failure. Further details about how material failure and local buckling are calculated and constrained may be found in the authors' previous paper [10]. The same material scatter knockdown factors (shown in Table 1) and barely visible impact damage knockdown factor $(0.65)$ are used in this study. In this study, in order to structurally constrain vertical lifting

Table 1: Material Scatter Knockdown Factors

\begin{tabular}{cccccc}
\hline Material & $k_{1}^{+}$ & $k_{1}^{-}$ & $k_{2}^{+}$ & $k_{2}^{-}$ & $k_{12}$ \\
\hline CFRP tape & 0.625 & 0.762 & 0.803 & 1.0 & 0.920 \\
CFRP fabric & 0.764 & 0.776 & 0.719 & 0.859 & 1.0 \\
\hline
\end{tabular}

surfaces, we also chose to constrain material failure and local buckling at the aircraft dive speed assuming a sideslip angle of $22.5^{\circ}$. This angle was chosen based on the maneuvering load requirements found in CFR 23.441 .

\section{Stability Constraints}

We calculate coupled flight and aeroelastic stability (including flutter) at the numbered operating points in Fig. 2 using ASWING's eigenmode analysis. The real parts of all eigenvalues are then constrained to lie in the left half of the complex plane to ensure a stable aircraft design. We provide details of this stability constraint formulation in our previous paper [10]. In addition to the stability constraints implemented at the three numbered operating points shown in Fig. 2, we also test for stability at one half of the aircraft dive speed, however, since trimmed flight 


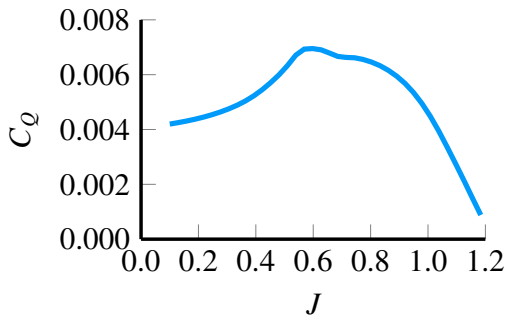

(a) Torque Coefficient

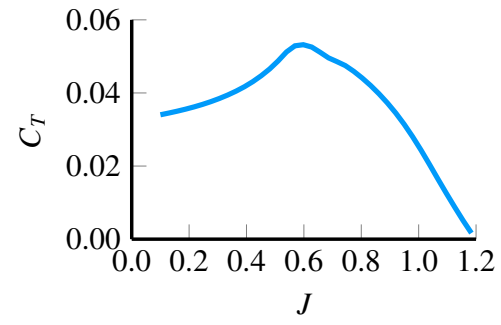

(b) Thrust Coefficient

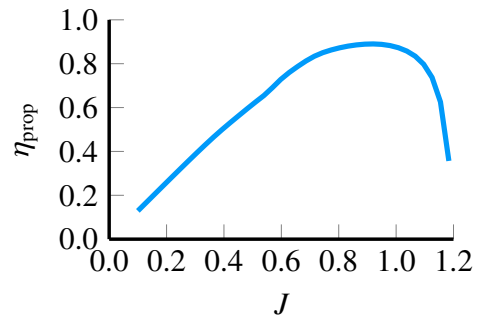

(c) Efficiency

Figure 1: Assumed propeller non-dimensional properties

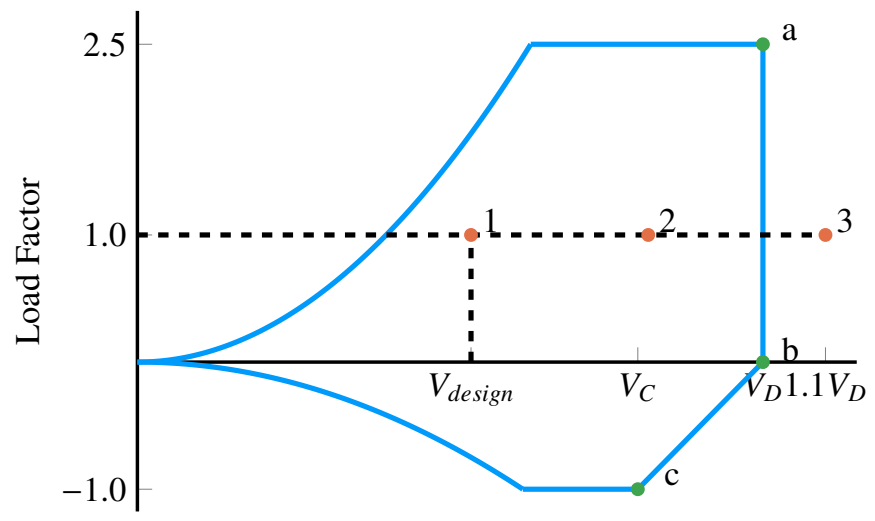

Figure 2: Flight envelope of SR-HALE aircraft in this study. $V_{C}$ is set to be $5 \mathrm{~m} / \mathrm{s}$ EAS above the design speed. $V_{D}$ is set to $1.25 V_{C}$. Lettered operating points are tested for material failure and local buckling. Numbered operating points are tested for aerostructural stability, material failure, and local buckling.

may not be possible at this airspeed, we fix flap deflections and angle of attack at zero.

In this study, we also constrain several stability derivatives. We compute two sets of stability derivatives using ASWING, one assuming quasi-steady aeroelastic loads and one assuming a rigid aircraft shape (after applying the deformations due to design operating conditions). We constrain static margin to be greater than $10 \%, C_{N_{\beta}}$ to be positive and $C_{l_{\beta}}$ to be negative for both sets of stability derivatives.

\section{Additional Mass and Drag}

To account for miscellaneous factors which increase aircraft mass and drag which are not explicitly modeled, we add a mass markup equal to $15 \%$ of the aircraft's mass and a drag markup equal to $10 \%$ of the aircraft's drag. The mass markup factor is applied to all aircraft components so that this additional mass is distributed throughout the aircraft.

\section{B. Solar Aircraft Configurations}

\section{Wing, Boom, and Tail Geometry}

For this study, we chose to optimize four separate solar aircraft configurations including an unswept flying wing aircraft, a swept flying wing aircraft, a single boom aircraft, and a twin-boom aircraft. We define the main wing in each case with four spanwise stations, as shown in Fig. 3, which may vary in length as chosen by the optimizer. Chord length, airfoil thickness, twist (defined normal to the wing for the swept-wing case), and spar cap width are specified at each station and linearly interpolated between stations. Dihedral is also specified by the optimizer between stations 2 and 3 and stations 3 and 4, except in the case of the swept flying wing aircraft, in which dihedral is fixed at zero everywhere except between stations 3 and 4 . We define the main wing's geometry for the unswept flying-wing configuration using the LA2573A airfoil family and define the main wing's geometry for all other configurations using the E216 airfoil family.

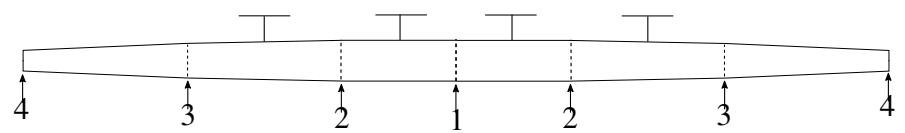

Figure 3: Spanwise properties of the main wing for all configurations in this study are defined at four spanwise stations and are linearly interpolated between stations.

Horizontal and vertical stabilizers are defined in the same manner as the wing, except that spanwise properties are only specified at the root and tip of each surface. Both horizontal and vertical stabilizer's geometry is defined by the symmetric four digit NACA airfoil series. No sweep or dihedral is applied to any tail surfaces.

Aircraft tails are attached by a constant radius boom which extends from the leading edge of the main wing to the trailing edge of the horizontal stabilizer. The length and radius of the boom(s) may vary as chosen by the optimizer. For the twin boom case, booms are attached at station 2 .

\section{Wing, Boom, and Tail Structure}

The structure for the wing as well as the vertical and horizontal stabilizers is a stiffened skin and box-beam configuration as shown in Fig. 4. Aircraft booms have the layup shown in Fig. 5. The primary structural

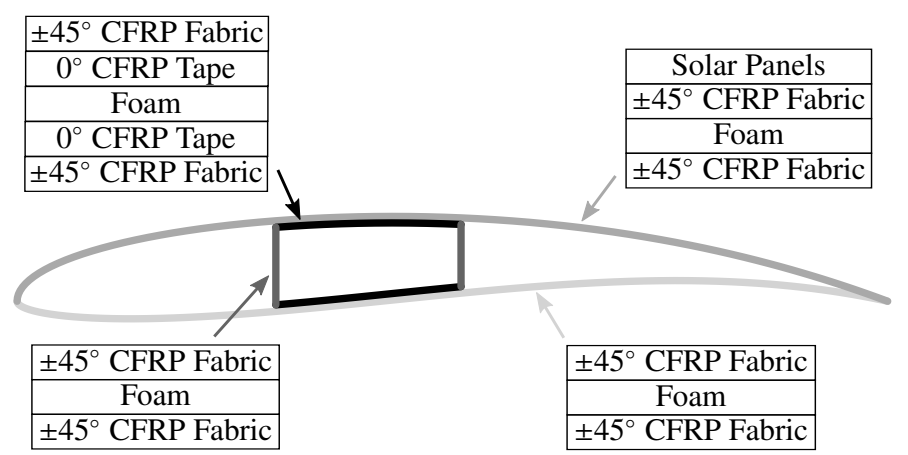

Figure 4: Box beam and stiffened skin configuration assumed in this study.

\begin{tabular}{|c|}
\hline $\pm 45^{\circ}$ CFRP Fabric \\
\hline $0^{\circ}$ CFRP Tape \\
\hline Foam \\
\hline $0^{\circ}$ CFRP Tape \\
\hline $\pm 45^{\circ}$ CFRP Fabric \\
\hline
\end{tabular}

Figure 5: Boom layup in this study. The boom is assumed to have circular cross-sections. 
material for all cases is carbon fiber reinforced polymer (CFRP), however, either standard or high modulus CFRP may be used. The properties we assume for standard and high modulus CFRP as well as for the foam we use are presented in Tables 2 and 3. For both lifting surfaces

Table 2: Assumed Material Stiffness Properties

\begin{tabular}{lcccccc}
\hline Material & $\begin{array}{c}E_{1} \\
(\mathrm{GPa})\end{array}$ & $\begin{array}{c}E_{2} \\
(\mathrm{GPa})\end{array}$ & $\begin{array}{c}G_{12} \\
(\mathrm{GPa})\end{array}$ & $v_{12}$ & $\begin{array}{c}\rho \\
\left(\mathrm{kg} / \mathrm{m}^{2}\right)\end{array}$ & $\begin{array}{c}t_{\text {ply }} \\
(\mathrm{mm})\end{array}$ \\
\hline $\begin{array}{l}\text { Standard } \\
\text { CFRP Tape }\end{array}$ & 135.0 & 10.0 & 5.0 & 0.30 & 1600 & $\geq 0.1$ \\
$\begin{array}{l}\text { Standard } \\
\begin{array}{l}\text { CFRP Fabric } \\
\text { High Modulus }\end{array}\end{array}$ & 70.0 & 70.0 & 5.0 & 0.10 & 1600 & $\geq 0.1$ \\
$\begin{array}{l}\text { CFRP Tape } \\
\begin{array}{l}\text { High Modulus } \\
175.0\end{array}\end{array}$ & 8.0 & 5.0 & 0.30 & 1600 & $\geq 0.1$ \\
$\begin{array}{l}\text { CFRP Fabric } \\
\text { Foam }\end{array}$ & 85.0 & 85.0 & 5.0 & 0.10 & 1600 & $\geq 0.1$ \\
\hline & 0.048 & 0.048 & 0.028 & 0.3 & 75.0 & $\geq 1$ \\
\hline
\end{tabular}

Table 3: Assumed Material Strength Properties

\begin{tabular}{|c|c|c|c|c|c|}
\hline Material & $\begin{array}{c}S_{1}^{+} \\
(\mathrm{MPa})\end{array}$ & $\begin{array}{c}S_{1}^{-} \\
(\mathrm{MPa})\end{array}$ & $\begin{array}{c}S_{2}^{+} \\
(\mathrm{MPa}) \\
\end{array}$ & $\begin{array}{c}S_{2}^{-} \\
(\mathrm{MPa}) \\
\end{array}$ & $\begin{array}{c}S_{12} \\
(\mathrm{MPa})\end{array}$ \\
\hline $\begin{array}{l}\text { Standard } \\
\text { CFRP Tape }\end{array}$ & 1500.0 & 1200.0 & 50.0 & 250.0 & 70.0 \\
\hline $\begin{array}{l}\text { Standard } \\
\text { CFRP Fabric }\end{array}$ & 600.0 & 570.0 & 600.0 & 570.0 & 90.0 \\
\hline $\begin{array}{l}\text { High Modulus } \\
\text { CFRP Tape }\end{array}$ & 1000.0 & 850.0 & 40.0 & 200.0 & 60.0 \\
\hline $\begin{array}{l}\text { High Modulus } \\
\text { CFRP Fabric }\end{array}$ & 350.0 & 150.0 & 350.0 & 150.0 & 35.0 \\
\hline
\end{tabular}

and booms, foam thicknesses and CFRP ply thicknesses are allowed to vary with a $1 \mathrm{~mm}$ and $0.1 \mathrm{~mm}$ lower bound respective. We allow CFRP ply thicknesses to vary continuously to simulate adding additional plies while maintaining the ability to use gradient-based optimization.

\section{Motors, Propellers, Batteries, and Payload}

Each of the aircraft configurations features four motors, propellers and associated batteries. The first motor, propeller, and battery set is located between stations 1 and 2, with its relative location specified by the optimizer. The second motor/propeller/battery set is located between stations 2 and 3, with its relative location also specified by the optimizer. No motor/propeller is located between stations 3 and 4, so that this section of the aircraft could be used as a winglet if necessary for stability. In all cases, relative motor, propeller, and battery set location is restricted to the center $90 \%$ of the section between the two adjacent airfoil stations. Motors cannot, therefore, be co-located with one of the stations. This restriction is placed to ensure a consistent paneling between spanwise breaks between design iterations, in order to ensure a continuous objective and constraint formulation for use with gradient-based optimization.

We model motors and propellers as $5 \mathrm{~kg}$ point masses located $1 \mathrm{~m}$ in front of the aircraft section they are attached to. We model batteries as point masses located at the quarter chord of the same section where motors and propellers are attached. We assume that the batteries are placed internally, so that they do not contribute to aircraft drag. The relative battery mass distribution between the inboard and outboard battery masses is varied by the optimizer, subject to the previously described constraint that the total battery energy storage be greater than the power required for night long flight. We assume the payload's mass is $10 \mathrm{~kg}$ and place it at the wing root semi-chord for all solar aircraft configurations.

\section{Mission Requirements}

We chose to constrain each aircraft configuration to be able to sustain year-round flight at latitudes up to $25^{\circ}$ at an altitude of $18 \mathrm{~km}$ carrying a $10 \mathrm{~kg}$ payload that requires $150 \mathrm{~W}$ of continuous power. We also assume the aircraft's avionics require $250 \mathrm{~W}$ of continuous power. We chose a latitude of $25^{\circ}$ because we wished to obtain a feasible aircraft design for all configurations. Results from studies performed by Colas et al. suggest that the feasibility of the solar aircraft mission may drop off sharply at higher latitudes. We chose an altitude of $18 \mathrm{~km}$ to avoid commercial and military air traffic (since U.S. regulated airspace ends near this altitude) and because there is a significant reduction in average wind speeds which occur at this altitude [18]. The payload mass and power requirements are the same as found in the optimization framework used by Colas et al.

\section{Results}

To evaluate the performance of each of configurations at accomplishing these mission objectives we decided to use our optimization framework to minimize total aircraft mass, since total aircraft mass is roughly proportional to total aircraft cost. The results from optimizing each configuration is presented in the following four sections.

\section{A. Unswept Flying Wing Aircraft}

We were not able to find a feasible solution for the unswept flying wing aircraft design, so we reduced the static margin requirement from $10 \%$ to 0 and re-optimized the design. We were then able to find a feasible solution for the high modulus CFRP case. The resulting design is shown in Fig. 6. Spanwise design variables for this design are presented in Table 4, with the remaining design variables shown in Table 12. Compared to the other configurations we optimized, this design is very heavy, with a mass of $478.31 \mathrm{~kg}$. Its planform area is also over twice as large as that of the swept flying wing aircraft $\left(79.58 \mathrm{~m}^{2}\right.$ compared to $35.84 \mathrm{~m}^{2}$ ).

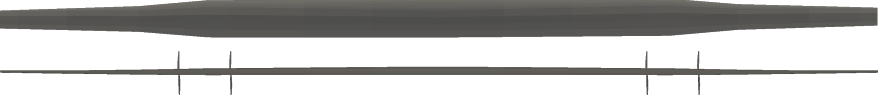

Figure 6: Top and rear view of the optimal unswept flying wing solar aircraft design during design operation.

The primary reason for the increased mass of this aircraft configuration is its size. One possible reason for the increased size is due to the use of the LA2573A airfoil for the unswept flying wing aircraft whereas the E216 airfoil was used on the other configurations in this study. While the reflexed nature of the LA2573A airfoil is necessary for an unswept flying wing aircraft, the E216 airfoil is designed for lower Reynolds numbers, which allows higher aspect ratios to be used at lower velocities. To test the performance of the E216 airfoil verse the LA2573A airfoil, we re-optimized the swept flying wing aircraft configuration using the LA2573A airfoil rather than the E216 airfoil. Doing so caused the size of the aircraft's planform area to increase from $35.84 \mathrm{~m}^{2}$ to $50.58 \mathrm{~m}^{2}$ and its mass to increase from $204.6 \mathrm{~kg}$ to $280.3 \mathrm{~kg}$, suggesting that at least part of the size (and mass) difference between the optimized unswept flying wing configuration and the swept flying wing configuration was due to the choice of airfoil.

Table 4: Unswept Flying Wing Final Spanwise Varying Design Variables

\begin{tabular}{lcccc}
\hline Design Variable & $\begin{array}{c}\text { Station } \\
1\end{array}$ & $\begin{array}{c}\text { Station } \\
2\end{array}$ & $\begin{array}{c}\text { Station } \\
3\end{array}$ & $\begin{array}{c}\text { Station } \\
4\end{array}$ \\
\hline Station Spanwise & 0.0 & 12.36 & 16.07 & 23.55 \\
Location $(\mathrm{m})$ & 2.066 & 1.974 & 1.364 & 0.944 \\
Chord $(\mathrm{m})$ & 0.137 & 0.144 & 0.146 & 0.100 \\
Airfoil Thickness & 8.53 & 5.80 & 6.60 & 3.08 \\
Ratio $(t / c)$ & 0.243 & 0.129 & 0.124 & 0.010 \\
Twist $\left({ }^{\circ}\right)$ & & & & \\
Spar Cap Width $(w / c)$ &
\end{tabular}

Active structural constraints at the end of the optimization include material failure at operating points "a" and "c", local buckling at operating point "a", both material failure and local buckling at the sideslip design condition, and stability at half the aircraft design speed. Other 
active constraints include energy, maximum lift coefficient, and $C_{N_{\beta}}$ constraints. Somewhat surprisingly, the reduced static margin constraint was not found to actively constrain this aircraft's design. Therefore, the impact of the static margin constraint on the design must come into play somewhere between a 0 and $10 \%$ static margin requirement.

\section{B. Swept Flying Wing Aircraft}

The optimized swept flying wing aircraft is shown in Fig. 7. Spanwise design variables are presented in Table 5 with the remaining design variables shown in Table 12. Optimized aircraft mass was lower when using standard CFRP compared to high modulus CFRP (204.6 kg compared to $222.3 \mathrm{~kg}$ ) so the results for the standard CFRP swept flying wing aircraft are presented in this paper.

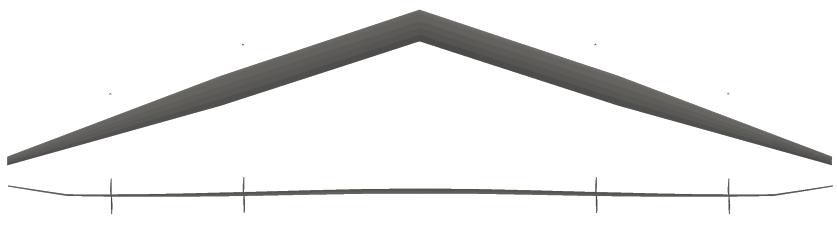

Figure 7: Top and rear view of the optimal swept flying wing aircraft design during design operation.

Table 5: Swept Flying Wing Final Spanwise Varying Design Variables

\begin{tabular}{lcccc}
\hline Design Variable & $\begin{array}{c}\text { Station } \\
1\end{array}$ & $\begin{array}{c}\text { Station } \\
2\end{array}$ & $\begin{array}{c}\text { Station } \\
3\end{array}$ & $\begin{array}{c}\text { Station } \\
4\end{array}$ \\
\hline Station Spanwise & 0.0 & 8.33 & 14.80 & 17.29 \\
Location $(\mathrm{m})$ & 1.328 & 1.247 & 0.606 & 0.360 \\
Chord $(\mathrm{m})$ & 0.118 & 0.116 & 0.100 & 0.117 \\
Airfoil Thickness & 5.97 & 2.78 & 2.77 & 3.87 \\
Ratio $(t / c)$ & 0.057 & 0.031 & 0.010 & 0.010 \\
Twist $\left({ }^{\circ}\right)$ & & & \\
Spar Cap Width $(w / c)$ & & \\
\hline
\end{tabular}

Active structural constraints at the end of the optimization include local buckling at operating points "a" and 3, stability constraints at operating points 2 and 3, and the stability constraints at half the aircraft design speed. The aircraft is therefore stability, rather than material failure constrained, however as discussed previously total aircraft mass actually increases when high modulus CFRP is used rather than standard CFRP. This is because using high modulus CFRP may cause material failure constraints to become active, which in this case causes a net increase in mass.

Other active constraints include static margin, maximum lift coefficient, and battery mass constraints. Notably missing is the energy deficit constraint, so more than enough energy is available during the day to sustainably power flight during winter solstice for the operating conditions, technology, and mission requirements assumed in this study. Energy deficit constraints also do not constrain the two tailed configurations which are discussed later in this paper, even though the solar efficiency assumed in this study is only $20 \%$, therefore even greater mass decreases are likely possible if potential energy storage is also considered.

\section{Single Boom Aircraft Configuration}

The optimized single boom aircraft is shown in Fig. 8. Spanwise design variables are presented in Tables 6 to 8 for the main wing, horizontal tail, and vertical tail, respectively. Remaining design variables are presented in Table 12. The optimized aircraft mass for the standard CFRP case was $186.0 \mathrm{~kg}$ and the optimized aircraft mass for the high modulus CFRP case was $228.3 \mathrm{~kg}$, therefore we present the results for the standard CFRP single boom configuration in this section.

Examining the flexibility seen in Fig. 8 suggests that the optimizer is judiciously placing battery mass and/or propellers in order to provide load alleviation. The lower relative mass of the single boom aircraft

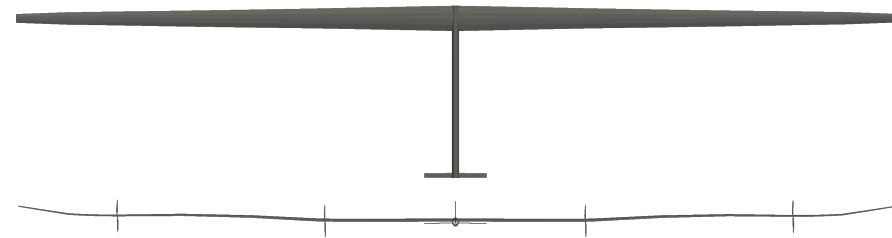

Figure 8: Top and rear view of the optimized single boom solar aircraft design during design operation.

Table 6: Single Boom Main Wing Final Spanwise Varying Design Variables

\begin{tabular}{lcccc}
\hline Design Variable & $\begin{array}{c}\text { Station } \\
1\end{array}$ & $\begin{array}{c}\text { Station } \\
2\end{array}$ & $\begin{array}{c}\text { Station } \\
3\end{array}$ & $\begin{array}{c}\text { Station } \\
4\end{array}$ \\
\hline \hline Station Spanwise & 0.0 & 6.89 & 17.79 & 20.61 \\
Location $(\mathrm{m})$ & 1.114 & 0.878 & 0.558 & 0.410 \\
Chord $(\mathrm{m})$ & 0.100 & 0.115 & 0.100 & 0.125 \\
Airfoil Thickness & 2.40 & 5.13 & 4.66 & 3.69 \\
Ratio $(t / c)$ & 0.016 & 0.01 & 0.01 & 0.01 \\
Twist $\left({ }^{\circ}\right)$ & & & & \\
Spar Cap Width $(w / c)$ &
\end{tabular}

Table 7: Single Boom Horizontal Stabilizer Final Spanwise Varying Design Variables

\begin{tabular}{lcc}
\hline \multicolumn{1}{c}{ Design Variable } & Station 1 & Station 2 \\
\hline Station Spanwise Location $(\mathrm{m})$ & 0.0 & 1.49 \\
Chord $(\mathrm{m})$ & 0.229 & 0.200 \\
Airfoil Thickness Ratio $(t / c)$ & 0.132 & 0.134 \\
Twist $\left({ }^{\circ}\right)$ & -0.15 & -4.95 \\
Spar Cap Width $(w / c)$ & 0.10 & 0.10 \\
\hline
\end{tabular}

Table 8: Single Boom Vertical Stabilizer Final Spanwise Varying Design Variables

\begin{tabular}{lcc}
\hline \multicolumn{1}{c}{ Design Variable } & Station 1 & Station 2 \\
\hline Station Vertical Location $(\mathrm{m})$ & 0.0 & 0.96 \\
Chord $(\mathrm{m})$ & 0.204 & 0.200 \\
Airfoil Thickness Ratio $(t / c)$ & 0.120 & 0.119 \\
Spar Cap Width $(w / c)$ & 0.40 & 0.10 \\
\hline
\end{tabular}


configuration compared to the swept flying wing configuration suggests that a boomed configuration is able to more efficiently address the various structural and performance solar aircraft constraints than swept flying wing aircraft can. Additionally, in this case, the boom of the aircraft did not need to be extended in front of the aircraft in order to provide a sufficient static margin, because the motors and propellers provide sufficient mass to move the aircraft's center of gravity forward to an acceptable location.

Active constraints for this configuration include stability constraints at all numbered operating points and at half the aircraft design speed. It is therefore likely that the choice of battery placement by the optimizer was in part to delay the onset of flutter. Material failure constraints were also active at a load factor of 2.5 and -1.0 as well as for the sideslip maneuvering load case. Other active constraints include maximum lift coefficient, battery mass, and $C_{N_{\beta}}$ constraints.

\section{Twin Boom Aircraft Configuration}

The optimized twin boom aircraft is shown in Fig. 9. Spanwise design variables are presented in Tables 9 to 11 for the main wing, horizontal tails, and vertical tails, respectively. Remaining design variables are presented in Table 12. We did not obtain a converged solution for the standard modulus twin-boom case, so the results in this section are for the high-modulus CFRP twin boom configuration. The total aircraft mass of this configuration is $251.1 \mathrm{~kg}$. This is a larger mass than those obtained for the single boom and swept flying wing aircraft configurations.

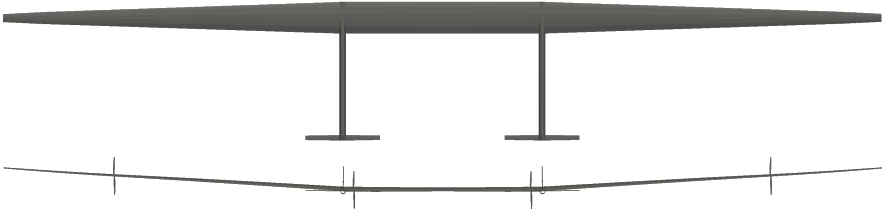

Figure 9: Top and rear view of the optimal twin boom solar aircraft design during design operation.

Table 9: Twin Boom Main Wing Final Spanwise Varying Design Variables

\begin{tabular}{lcccc}
\hline Design Variable & $\begin{array}{c}\text { Station } \\
1\end{array}$ & $\begin{array}{c}\text { Station } \\
2\end{array}$ & $\begin{array}{c}\text { Station } \\
3\end{array}$ & $\begin{array}{c}\text { Station } \\
4\end{array}$ \\
\hline Station Spanwise & 0.0 & 4.55 & 18.17 & 20.04 \\
Location $(\mathrm{m})$ & 1.441 & 1.441 & 0.541 & 0.357 \\
Chord $(\mathrm{m})$ & 0.100 & 0.100 & 0.100 & 0.119 \\
Airfoil Thickness & & & & \\
Ratio $(t / c)$ & 2.61 & 4.09 & 3.45 & 3.22 \\
Twist $\left({ }^{\circ}\right)$ & 0.064 & 0.064 & 0.01 & 0.01 \\
Spar Cap Width $(w / c)$ & & & & \\
\hline
\end{tabular}

Table 10: Twin Boom Horizontal Stabilizer Final Spanwise Varying Design Variables

\begin{tabular}{lcc}
\hline \multicolumn{1}{c}{ Design Variable } & Station 1 & Station 2 \\
\hline Station Spanwise Location $(\mathrm{m})$ & 0.0 & 1.70 \\
Chord $(\mathrm{m})$ & 0.249 & 0.195 \\
Airfoil Thickness Ratio $(t / c)$ & 0.138 & 0.117 \\
Twist $\left({ }^{\circ}\right)$ & -2.29 & 0.00 \\
Spar Cap Width $(w / c)$ & 0.10 & 0.10 \\
\hline
\end{tabular}

Active structural constraints at the end of the twin boom optimization include material failure constraints at load factors of 2.5, 0.0, and -1.0 as well as stability constraints at $110 \%$ of the dive speed and at half the aircraft design speed. Material failure and local buckling constraints were also active for the sideslip maneuvering load case. For this aircraft and for the single boom aircraft, tail section chords are constrained by Reynolds number constraints.
Table 11: Twin Boom Vertical Stabilizer Final Spanwise Varying Design Variables

\begin{tabular}{lcc}
\hline \multicolumn{1}{c}{ Design Variable } & Station 1 & Station 2 \\
\hline Station Vertical Location $(\mathrm{m})$ & 0.0 & 1.11 \\
Chord $(\mathrm{m})$ & 0.195 & 0.195 \\
Airfoil Thickness Ratio $(t / c)$ & 0.156 & 0.154 \\
Spar Cap Width $(w / c)$ & 0.1 & 0.1 \\
\hline
\end{tabular}

\section{Conclusions}

In this paper we examined the defining characteristics of solar aircraft configurations through gradient-based multidisciplinary design optimization. We optimized four solar aircraft configurations: an unswept flying wing configuration, a swept flying wing configuration, a single boom configuration, and a twin boom configuration. Our objective was to minimize aircraft mass, since aircraft mass is a rough metric for aircraft cost, while satisfying structural, aerodynamic, stability, and energy constraints. We found the single boom configuration to outperform the other configurations, in part because it was able to place batteries and propeller in such a manner to provide load alleviation. Future work involves investigating each of these configurations over a larger range of mission requirements.

\section{Acknowledgments}

The authors gratefully acknowledge support from the Utah NASA Space Grant Consortium.

\section{Citing this Work}

This paper was published in the proceedings of the AIAA Aviation 2019 Forum. Any citations of this work should use the following reference:

McDonnell, T. G. and Ning, A., An Examination into the Defining Characteristics of Flexible Solar Aircraft Configurations through Optimization, AIAA AVIATION Forum, American Institute of Aeronautics and Astronautics, June 2019

\section{References}

[1] Baldock, N. and Mokhtarzadeh-Dehghan, M., "A study of solarpowered, high-altitude unmanned aerial vehicles," Aircraft Engineering and Aerospace Technology, Vol. 78, No. 3, 2006, pp. 187-193.

[2] Cestino, E., "Design of solar high altitude long endurance aircraft for multi payload \& operations," Aerospace science and technology, Vol. 10, No. 6, 2006, pp. 541-550.

[3] Nickol, C., Guynn, M., Kohout, L., and Ozoroski, T., "High Altitude Long Endurance Air Vehicle Analysis of Alternatives and Technology Requirements Development," Aerospace Sciences Meetings, American Institute of Aeronautics and Astronautics, Jan. 2007, pp. -.

[4] Nickol, C. L., Guynn, M. D., Kohout, L. L., and Ozoroski, T. A., "High altitude long endurance UAV analysis of alternatives and technology requirements development," 2007

[5] Colas, D., Roberts, N. H., and Suryakumar, V. S., "HALE Multidisciplinary Design Optimization Part II: Solar-Powered Flying-Wing Aircraft," AIAA AVIATION Forum, American Institute of Aeronautics and Astronautics, June 2018, pp. -

[6] Colas, D., Roberts, N. H., and Suryakumar, V. S., "HALE Multidisciplinary Design Optimization Part I: Solar-Powered Single and MultipleBoom Aircraft," AIAA AVIATION Forum, American Institute of Aeronautics and Astronautics, June 2018, pp. -.

[7] Burton, M. and Hoburg, W., "Solar and Gas Powered Long-Endurance Unmanned Aircraft Sizing via Geometric Programming," Journal of Aircraft, Vol. 55, No. 1, Sept. 2017, pp. 212-225.

[8] Burton, M. J., Drela, M., Courtin, C., Colas, D., Suryakumar, V. S., and Roberts, N. H., "Solar Aircraft Design Trade Studies Using Geometric Programming," AIAA AVIATION Forum, American Institute of Aeronautics and Astronautics, June 2018, pp. - . 
[9] McDonnell, T. G., Mehr, J. A., and Ning, A., "Multidisciplinary Design Optimization Analysis of Flexible Solar-Regenerative High-Altitude Long-Endurance Aircraft," AIAA SciTech Forum, American Institute of Aeronautics and Astronautics, Jan. 2018.

[10] McDonnell, T. and Ning, A., "Gradient-Based Optimization of SolarRegenerative High-Altitude Long-Endurance Aircraft," 2019, In Review.

[11] Revels, J., Lubin, M., and Papamarkou, T., "Forward-Mode Automatic Differentiation in Julia," arXiv:1607.07892 [cs.MS], 2016.

[12] Drela, M., "Integrated simulation model for preliminary aerodynamic, structural, and control-law design of aircraft," Structures, Structural Dynamics, and Materials and Co-located Conferences, American Institute of Aeronautics and Astronautics, April 1999.

[13] Bir, G. S., User's guide to PreComp (Pre-Processor for Computing Composite Blade Properties), Golden, Colo. : National Renewable Energy Laboratory,, 2006.

[14] Drela, M., "XFOIL: An analysis and design system for low Reynolds number airfoils," Low Reynolds number aerodynamics, Springer, 1989, pp. 112 .

[15] Gueymard, C., SMARTS2: a simple model of the atmospheric radiative transfer of sunshine: algorithms and performance assessment, Florida Solar Energy Center Cocoa, FL, 1995.

[16] Gates, N. S., Moore, K. R., Ning, A., and Hedengren, J. D., "Combined Trajectory, Propulsion, and Battery Mass Optimization for SolarRegenerative High-Altitude Long Endurance Unmanned Aircraft," AIAA Scitech 2019 Forum, San Diego, CA, Jan. 2019.

[17] Moore, K. R. and Ning, A., "Distributed Electric Propulsion Effects on Traditional Aircraft Through Multidisciplinary Optimization," AIAA SciTech Forum, American Institute of Aeronautics and Astronautics, 2018.

[18] Gavan, J., Tapuchi, S., and Grace, D., "Concepts and main applications of high-altitude-platform radio relays," URSI Radio Science Bulletin, Vol. 2009, No. 330, 2009, pp. 20-31.

[19] McDonnell, T. G. and Ning, A., "An Examination into the Defining Characteristics of Flexible Solar Aircraft Configurations through Optimization," AIAA AVIATION Forum, American Institute of Aeronautics and Astronautics, June 2019. 
Table 12: Final Design Variables

\begin{tabular}{|c|c|c|c|c|}
\hline Design Variable & Unswept & Swept & Single & Twin \\
\hline Design Velocity $(\mathrm{m} / \mathrm{s})$ & 33.18 & 30.88 & 29.78 & 30.50 \\
\hline Wing Span (m) & 47.10 & 34.57 & 41.21 & 40.08 \\
\hline Sweep $\left({ }^{\circ}\right)$ & N/A & 18.24 & N/A & N/A \\
\hline Wing Dihedral from station 2 to station $3\left(^{\circ}\right)$ & 0.0 & 0.0 & N/A & 2.78 \\
\hline Wing Dihedral from station 3 to station $4\left(^{\circ}\right)$ & 0.0 & 7.34 & 8.15 & 2.78 \\
\hline Wing Distance to First Web $(x / c)$ & 0.04 & 0.085 & 0.124 & 0.086 \\
\hline CFRP Tape Thickness (mm) & 0.43 & 0.75 & 0.10 & 0.57 \\
\hline CFRP Fabric Thickness (mm) & 0.10 & 0.10 & 0.10 & 0.10 \\
\hline Skin Foam Thickness (mm) & 1.0 & 1.0 & 1.0 & 1.0 \\
\hline Spar Foam Thickness (mm) & 1.0 & 1.6 & 1.0 & 1.0 \\
\hline Web Foam Thickness (mm) & 1.0 & 1.0 & 1.0 & 1.0 \\
\hline $\begin{array}{l}\text { Inboard battery/motor/propeller spanwise distance from } \\
\text { station } 1 \text { to station } 2\end{array}$ & $10.0 \%$ & $88.6 \%$ & $93.4 \%$ & $88.8 \%$ \\
\hline $\begin{array}{l}\text { Outboard battery/motor/propeller spanwise distance } \\
\text { from station } 2 \text { to station } 3\end{array}$ & $20.2 \%$ & $71.2 \%$ & $84.9 \%$ & $76.5 \%$ \\
\hline Inboard Battery Mass (kg) & 102.71 & 41.89 & 29.40 & 34.48 \\
\hline Outboard Battery Mass (kg) & 14.59 & 4.72 & 13.29 & 22.96 \\
\hline Propeller Diameter (m) & 2.33 & 1.49 & 1.48 & 1.73 \\
\hline Advance Ratio $(V / n D)$ & 0.916 & 0.915 & 0.913 & 0.913 \\
\hline Motor Kv $(\mathrm{rpm} / \mathrm{V})$ & 33.26 & 165.8 & 32.0 & 32.0 \\
\hline Motor No-Load Current (A) & 1.80 & 3.01 & 0.518 & 0.770 \\
\hline Horizontal Stabilizer Distance to First Web $(x / c)$ & N/A & N/A & 0.01 & 0.19 \\
\hline Vertical Stabilizer Distance to First Web $(x / c)$ & N/A & N/A & 0.12 & 0.48 \\
\hline Boom Length (m) & N/A & N/A & 8.00 & 5.46 \\
\hline Boom Radius (m) & N/A & N/A & 0.15 & 0.15 \\
\hline Boom CFRP Tape Thickness (mm) & N/A & N/A & 0.13 & 0.57 \\
\hline Boom CFRP Fabric Thickness (mm) & N/A & N/A & 0.1 & 0.1 \\
\hline Boom Foam Thickness (mm) & N/A & N/A & 2.2 & 1.7 \\
\hline
\end{tabular}

